\title{
Minireview Cancer treatment with kinase inhibitors: what have we learnt from imatinib?
}

\author{
DM Ross' and TP Hughes*,1 \\ 'Division of Haematology, Institute of Medical and Veterinary Science, PO Box 14 Rundle Mall, Adelaide SA 5000, Australia
}

\begin{abstract}
Over the past few years, a number of anticancer drugs have been developed that specifically target kinases known to be oncogenic. The leading drug in this area is imatinib mesylate, which targets ABL, KIT and PDGFR. It has been remarkably effective in the treatment of chronic myeloid leukaemia, although resistance remains a significant problem. From the imatinib experience in this setting, we present some principles of kinase inhibition that may have more general applicability in targeted anticancer therapy. It is clear that the identification of appropriate targets (activated kinases) and monitoring levels of response (to recognise emerging resistance) are essential to optimise clinical management.
\end{abstract}

British Journal of Cancer (2004) 90, 12-19. doi:I0.1038/sj.bjc.660I507 www.bjcancer.com

(c) 2004 Cancer Research UK

Kinases play a fundamental role in many cancers. Kinase inhibition represents a promising new anticancer strategy. The first kinase inhibitor to be developed for clinical use is imatinib mesylate (Glivec, Novartis), which was designed for use in chronic myeloid leukaemia (CML). In CML, the Philadelphia chromosome $(\mathrm{Ph})$ and variants result in a translocation that codes for the chimaeric fusion protein, BCR-ABL, which is a constitutively activated kinase. Imatinib inhibits the normal Abelson tyrosine kinase $(\mathrm{ABL})$ as well as $\mathrm{BCR}-\mathrm{ABL}$.

Imatinib inhibits other tyrosine kinases broadening the potential therapeutic utility to a range of neoplastic disorders (Buchdunger et al, 2002). The proto-oncogene C-KIT encodes the KIT tyrosine kinase, which serves as a receptor for stem cell factor. KIT is important in cell cycle regulation and critically important in haematopoiesis. Two receptors for platelet-derived growth factor (PDGF) are sensitive to imatinib. PDGF is involved in cell cycle regulation, angiogenesis, and fibroblast proliferation (ClaessonWelsh, 1994). Despite similarities in structure and function, PDGFR $\alpha$ and $\beta$ are encoded on different chromosomes and differ in their affinity for individual isotypes of PDGF.

We review the current evidence regarding efficacy and safety of imatinib in Philadelphia-positive $(\mathrm{Ph}+)$ haematological disorders and in other disorders with evidence for imatinib sensitivity. We also review the available data on imatinib resistance. We then consider the broader implications for anticancer treatment based on kinase inhibitors.

\section{EFFICACY}

\section{Chronic myeloid leukaemia}

CML is a disorder of the haematopoietic stem cell consistently associated with the $B C R-A B L$ fusion gene. It is characterised by the

*Correspondence: Dr TP Hughes; E-mail: timothy.hughes@imvs.sa.gov.au Received II August 2003; revised 31 October 2003; accepted 31 October 2003 proliferation of the myeloid series, although lymphoid cells may also arise from the malignant clone. Three phases of the disease are recognised. In the chronic phase, there is indolent leukocytosis with infiltration of the liver and spleen. In the accelerated phase, there may also be acquisition of additional cytogenetic abnormalities and an increase in the proportion of immature cells in the blood or marrow. In blast crisis, which may be of lymphoid or myeloid lineage, the clinical picture resembles de novo acute leukaemia and carries a very poor prognosis.

\section{Imatinib in newly diagnosed chronic phase}

Prior to the introduction of imatinib, the accepted standard therapy for newly diagnosed CML in the chronic phase was interferon $\alpha$ and cytarabine. A recently published study (O'Brien et al, 2003) randomised 1106 patients to interferon-cytarabine combination therapy or imatinib at a dose of $400 \mathrm{mg}$ daily. With a median follow-up of 19 months, no difference in the overall survival could be demonstrated. However, crossover to imatinib therapy occurred in 318 out of 553 patients (58\%) in the interferon-cytarabine group, largely due to intolerance of interferon-related side effects. The rates of complete haematologic response (CHR) (95 vs 56\%), complete cytogenetic response (CCR: 76 vs $15 \%$ ) and freedom from progression to accelerated phase or blast crisis (97 vs 92\%), all showed a statistically significant improvement in the imatinib group.

\section{Imatinib in chronic phase after interferon failure}

Patients with prior exposure to interferon are mostly in the late chronic phase ( $\geqslant 12$ months from diagnosis). Of 454 late chronic phase patients started on imatinib at $400 \mathrm{mg}$ daily, $95 \%$ achieved CHR and $41 \%$ CCR with freedom from progression in $89 \%$ at 18 months (Kantarjian et al, 2002). These results for imatinib therapy are inferior to those observed in patients treated at diagnosis.

Two studies have looked at dose escalation in order to improve the response rates in this group. With imatinib treatment at $800 \mathrm{mg}$ daily in interferon-failed chronic phase (Cortes et al, 2003), CHR 
was achieved in $100 \%$ and major cytogenetic response (MCR) in $90 \%$. After 3 months, dose reduction due to toxicity had occurred in $42 \%$, with the most common grade III - IV toxicities being haematological. Among patients started on imatinib $400 \mathrm{mg}$ daily, dose escalation was an effective salvage therapy for refractoriness or relapse (Kantarjian et al, 2003), but the overall results with this strategy were inferior to those reported with treatment initiated at a higher dose.

\section{Imatinib in accelerated phase}

The accelerated phase of CML typically follows several years of chronic phase and is associated with decreased response to therapy and a shortened median survival of less than 1 year. A multicentre study reporting on 181 patients treated with imatinib for accelerated phase CML suggests lower response rates and increased toxicity in comparison with the chronic phase (Talpaz et al, 2002). Patients were initially commenced on imatinib at $400 \mathrm{mg}$ daily, but after efficacy and safety data became available, subsequent patients were treated with $600 \mathrm{mg}$ daily. CHR was achieved in 53\% and sustained for at least 1 month in 34\%. CCR was achieved in $17 \%$. With a median follow-up in excess of 10 months, there was a significant improvement in overall survival and freedom from progression for the higher dose group. Grade III-IV haematological toxicity occurred in $58 \%$ and severe nonhaematological toxicity was uncommon $(<5 \%)$.

\section{Imatinib in blast crisis and $\mathrm{Ph}+$ acute lymphoblastic leukaemia (ALL)}

In blast crisis of $\mathrm{CML}$ and in de novo $\mathrm{Ph}+\mathrm{ALL}, \mathrm{BCR}-\mathrm{ABL}$ retains sensitivity to imatinib, but additional genetic abnormalities conferring drug resistance are common. In patients with relapsed or refractory $\mathrm{Ph}+\mathrm{ALL}$ or lymphoid blast crisis (Ottmann et al, 2002) and in myeloid blast crisis (Sawyers et al, 2002), CHR was achieved in around $20 \%$. Despite good haematological response, in most cases relapse occurred early with a median survival of only $20-30$ weeks. Relapse is commonly associated with emergence of mutations in the BCR-ABL kinase (Gorre et al, 2001; von Bubnoff et al, 2002).

\section{Other myeloid disorders}

A clinical phenotype closely mimicking CML has been described in a patient carrying a BCR-PDGFRA fusion gene (Baxter et al, 2002). Response to imatinib was not tested. This, and potentially other fusion kinases, may account for the rare cases of otherwise typical CML, which lack $B C R-A B L$.

The cytogenetic abnormality $t(5 ; 12)$ has been described in a rare myeloproliferative disorder with leukocytosis and eosinophilia. Splenomegaly and skin infiltration may be present. The translocation is usually associated with a fusion of TEL (a regulatory gene that may be translocated in acute leukaemia) and PDGFRB (Apperley et al, 2002). Four patients with myeloproliferative disorder and confirmed PDGFRB fusion were treated with imatinib $400 \mathrm{mg}$ daily. All achieved CHR after 4 weeks and cytogenetic remission after 9 months.

Idiopathic hypereosinophilic syndrome is characterised by persistent peripheral blood eosinophilia with evidence of endorgan damage (usually cardiac or sinopulmonary infiltration or neuropathy) without an identifiable cause. In a series of 16 patients with idiopathic hypereosinophilic syndrome, a novel fusion of PDGFRA and FIP1L1 has been reported (Cools et al, 2003). Nine patients were found to have this fusion gene, with eight of these having a cryptic deletion of chromosome 4 . Five of these nine patients and a further five patients without PDGFRA-FIP1L1 fusion received imatinib treatment. The doses of imatinib ranged from 100 to $400 \mathrm{mg}$ daily. CHR of at least 3 months duration was achieved in all but two patients, neither of whom carried the fusion gene. Efficacy at lower doses than in CML is supported by in vitro data, indicating that the $\mathrm{IC}_{50}$ (drug concentration required to inhibit proliferation by 50\%) for imatinib of PDGFR $\alpha$-FIP1L1 is approximately 2-log lower than for BCR-ABL.

Imatinib-responsive idiopathic hypereosinophilic syndrome without an identified molecular abnormality has also been reported elsewhere (Ault et al, 2002; Gleich et al, 2002). Gleich et al report on five patients treated with imatinib. Four patients achieved CHR. The starting dose was $100 \mathrm{mg}$ daily and maintenance doses were as low as $200 \mathrm{mg}$ per week. These results imply that another cryptic rearrangement involving PDGFR (or another imatinib-sensitive kinase) may be present in some patients.

Systemic mastocytosis is a rare myeloproliferative disorder with an increase in mast cells in the marrow and evidence of visceral and cutaneous infiltration. A syndrome related to histamine release may also occur. Imatinib inhibition of KIT phosphorylation in mast cell lines correlates with the inhibition of cellular proliferation (Zermati et al, 2003), suggesting that the cells are critically dependent on KIT activity. In systemic mastocytosis, the most common activating mutation in C-KIT D816V, occurs in the catalytic region of the enzyme, and also prevents binding of imatinib. Most cases of mastocytosis are therefore resistant to imatinib. However, patients with mutations in the juxtamembrane region of the KIT molecule may retain in vitro sensitivity (Zermati et al, 2003) and durable clinical responses to imatinib in doses of $400 \mathrm{mg}$ daily or less have been demonstrated (Pardanani et al, 2002).

The importance of PDGF in the development of fibrosis and of KIT in haematopoiesis makes idiopathic myelofibrosis an appealing target for imatinib therapy. However, the results of treatment have been mixed. The results of a phase 2 trial of imatinib in 23 patients with idiopathic myelofibrosis (Tefferi et al, 2002) were disappointing. Partial responses were observed in some patients, but no clinically significant benefit was obtained and haematological toxicity was greater than that observed in the chronic phase of CML, despite use of the standard starting dose of $400 \mathrm{mg}$ daily. On the other hand, Cortes et al. (2002) observed improvement in cell counts or reduction in the spleen size in over $50 \%$ of 18 patients treated with the same dose of imatinib.

A study using C-KIT antisense oligonucleotides in vitro suggests that normal erythropoiesis is significantly dependent on KIT function (Ratajczak et al, 1992). In polycythaemia rubra vera, although the expression of KIT is normal, an increased sensitivity of the receptor to its ligand, stem cell factor, has been observed (Dai et al, 1994). These observations provide a rationale for the trials of imatinib in this myeloproliferative disorder. Reports in the small numbers of patients report reduced phlebotomy requirement with imatinib treatment (Cortes et al, 2002; Silver, 2002; Jones and Dickinson, 2003).

In acute myeloid leukaemia (AML), KIT is expressed in at least two-thirds of cases, although the number with C-KIT mutations is much smaller. In a series of de novo childhood AML (Zwaan et al, 2002), C-KIT was found to be mutated in $6.4 \%$ with the imatinibresistant $\mathrm{D} 816 \mathrm{~V}$ mutation accounting for approximately half of these. An in vitro study using leukaemic cells from 12 patients found an overall poor response to imatinib at pharmacological doses (Scappini et al, 2001), although there was significant heterogeneity between leukaemia samples. This most likely reflects that in most cases of AML, KIT is not critically involved in sustaining abnormal proliferation, unlike BCR-ABL, which is pathogenetic in CML. Similarly, among 17 KIT-positive patients with relapsed or refractory AML treated with imatinib monotherapy, there were no haematological remissions (Cortes et al, 2002). Despite these negative findings, imatinib-responsive AML has been reported, with some cases achieving CHR (Fischer et al, 2002; Kindler et al, 2003). The clarification of the molecular pathways involved in such cases may help identify a subset of AML that will benefit from imatinib treatment. 


\section{Gastrointestinal stromal tumours}

Constitutive activation of KIT is almost universal in gastrointestinal stromal tumours (GIST), and often associated with gain-offunction mutations in C-KIT. A study of material from GISTs of 48 patients revealed mutations in $C$-KIT in $92 \%$, with the majority located in exon 11, which encodes the juxtamembrane region involved in activating dimerisation (Rubin et al, 2001).

Interestingly, a recent report found that among the small percentage of $C$-KIT wild-type GISTs, approximately one-third had mutations in the PDGFRA gene with evidence of abnormal activation of its tyrosine kinase (Heinrich et al, 2003). This overlap in disease phenotypes associated with mutations in different tyrosine kinases is mirrored in the myeloproliferative disorders with eosinophilia, and highlights the case for accurate genetic diagnosis.

Impressive activity of imatinib monotherapy has been demonstrated in a single study of 147 patients with unresectable or metastatic GIST (Demetri et al, 2002), despite refractoriness to conventional chemoradiotherapy. Partial response (reduction in tumour volume $\geqslant 50 \%$ ) was achieved in $54 \%$, with only $14 \%$ showing evidence of disease progression at a median follow-up of 288 days. The median time to measurable response was 13 weeks. The median time to disease progression was not reached within 288 days. Within the study there was a randomisation of imatinib dose (400 vs $600 \mathrm{mg}$ daily). There was no significant difference in the response or toxicity between the two groups. However, nine patients with disease progression on the lower dose were crossed over to the higher dose and three achieved improvement in disease control.

\section{Other solid tumours}

The expression of KIT or PDGFR $\beta$ has been observed in a number of solid tumours, including small cell lung cancer, thyroid cancer, ovarian and breast cancers, prostate cancer, seminoma, glioblastoma, and dermatofibrosarcoma protruberans. For some of these tumours, there is in vitro evidence of inhibition by imatinib (Buchdunger et al, 2002; Heinrich et al, 2002a). In contrast to CML, the inhibition of a single signalling pathway will not usually be sufficient to overcome the proliferative advantage of the tumour. Clinical efficacy data are awaited.

\section{Diagnosis and monitoring}

Chronic myeloid leukaemia is one of very few diseases for which there is a universally identifiable, single genetic abnormality that provides an ideal target for therapy. In CML, the demonstration of $B C R-A B L$ confirms suitability for therapy, as well as providing a target for disease monitoring. Diagnostic and monitoring strategies for CML and other imatinib-sensitive disorders are presented below and summarised in Table 1 .

Quantitative monitoring of $B C R-A B L$ mRNA by reverse transcriptase PCR is used to follow response. Progressive reduction in $B C R-A B L$ levels may be observed over a long period, sometimes in excess of 1 year before reaching a plateau. Increases in $B C R-A B L$ levels are observed with the development of resistance to therapy (Hughes and Branford 2003). A single institution study of 120 late chronic phase (interferon resistant or intolerant) patients (Merx et al, 2002) monitored response to imatinib (400 mg daily) with peripheral blood quantitative real-time polymerase chain reaction (qPCR) for $B C R-A B L$ mRNA. There was a strong correlation between bone marrow karyotype $(\% \mathrm{Ph}+$ metaphases) and the $B C R-A B L / A B L$ ratio by qPCR. In addition, the level of $B C R-A B L$ at 2 months was predictive of cytogenetic response at 6 months. At least in the short term, attainment of a major cytogenetic response ( $\leqslant 35 \% \mathrm{Ph}+$ metaphases) is associated with a survival advantage. It seems likely that the kinetics of qPCR response will become a useful prognostic marker to identify highrisk individuals who may not respond well to imatinib monotherapy.

In other imatinib-responsive disorders, despite greater genetic heterogeneity, molecular diagnosis and monitoring should be the goal. At least in the case of myeloproliferative disorders (e.g. PDGFRA-FIP1L1 fusion, Cools et al), there is evidence that this will be possible. Where the molecular abnormality has not been identified, there may still be a role for other biological markers of imatinib responsiveness. For example, the inhibition of abnormal phosphorylation of target molecules should potentially be measurable in any imatinib-sensitive disorder, although in the case of solid tumours availability of tumour tissue may limit monitoring options.

The functional monitoring of a subset of 64 GIST patients of Demetri et al. (2002) was undertaken with ${ }^{18}$ fluoro-deoxy-glucose positron emission tomography (PET) in addition to standard radiological imaging. All patients who achieved a response had a reduction in PET activity from baseline. PET responses occurred early (even within $24 \mathrm{~h}$ ). Loss of response was associated with increased PET activity in all cases. Furthermore, a later report (van den Abbeele et al, 2002) showed that PET response within the first month of imatinib therapy was a strong predictor of progression-free survival over the subsequent 16 months of follow-up.

Preliminary data on the genetic prediction of imatinib response in GIST were presented by Heinrich et al. (2002b). They undertook mutation detection in C-KIT in 121 cases of unresectable GIST and correlated these findings with the clinical course of the disease. The presence of mutations in exon 11 predicted both significantly higher rates of response to imatinib (72 vs 32\%) and longer time to treatment failure. In contrast, in an earlier study, in patients treated without imatinib, exon 11 mutation was found to be an independent adverse prognostic factor in multivariate analysis (Singer et al, 2002). In the future, the detection of specific C-KIT mutations may be used to guide imatinib dosing or combination therapy in GIST patients.

\section{TOXICITY}

Typically, in CML at the commencement of imatinib therapy, haematopoiesis is almost exclusively derived from the $B C R-A B L$

Table I Diagnosis and monitoring of imatinib-sensitive disorders

\begin{tabular}{|c|c|c|c|}
\hline Disorder & Genetics & Diagnosis & Monitoring \\
\hline CML & $B C R-A B L$ fusion & Karyotype, PCR & $\begin{array}{l}\text { Karyotype quantitative PCR BCR- } \\
\text { ABL mutation screening }\end{array}$ \\
\hline Hyper-eosinophilic syndromes & Various involving PDGFRA and PDGFRB & Karyotype, PCR & $\begin{array}{l}\text { Karyotype quantitative PCR } \\
\text { mutation screening }\end{array}$ \\
\hline Systemic mastocytosis & C-KIT activating mutation & $\begin{array}{l}\text { KIT immunohistochemistry, C-KIT } \\
\text { mutation detection }\end{array}$ & \\
\hline Gastrointestinal stromal tumours & C-KIT activating mutation & $\begin{array}{l}\text { KIT immunohistochemistry, C-KIT } \\
\text { mutation detection }\end{array}$ & PET \\
\hline
\end{tabular}


positive clone. Inhibition of this clone will inevitably result in cytopenia until there is a recovery of the suppressed residual normal haematopoiesis. Clinical trials in the different phases of CML indicate an increase in haematological toxicity with more advanced disease. Doses beyond $600 \mathrm{mg}$ daily appeared to be associated with increased toxicity. Even with higher rates of cytopenia, dose-limiting and fatal toxicities were relatively uncommon.

In contrast, in GIST there was little evidence of an effect on normal haematopoiesis, as grade III - IV thrombocytopenia did not occur and grade IV neutropenia was reported in only $5 \%$. The rates of nonhaematological toxicity appear similar in all trials for both CML and GIST and the drug is generally well-tolerated.

While the short-term side effects of imatinib are generally welldocumented, the potential longer-term consequences of kinase blockade remain uncertain. Extrapolation from observations in animal models is difficult as inhibition of kinase function in a mature animal will clearly not produce the range of developmental anomalies seen in germline knockout studies. In addition, some tyrosine kinase-dependent defects may become significant only in stressed conditions, such as inflammation and tissue repair (Van Etten, 1999). However, in knockout mice there is evidence of osteoporosis and defective osteoblast maturation (Li et al, 2000); defects in spermatogenesis (Guerif et al, 2002); abnormal lymphoid proliferation and differentiation, and abnormal melanin metabolism (Van Etten, 1999; Hou et al, 2000). This latter observation is significant in view of clinical reports of hypopigmentation in patients receiving imatinib (Saikia et al, 2002; Hasan et al, 2003). Continuing surveillance for delayed effects of kinase blockade will be important.

\section{IMATINIB RESISTANCE}

Resistance has been studied extensively in CML, where acquired imatinib resistance is defined as a loss of established haematologic or cytogenetic response to imatinib, as opposed to primary resistance, in which no response is achieved. In CML, acquired resistance is usually associated with restoration of BCR-ABL kinase activity (Gorre et al, 2001). Data on resistance in other imatinibresponsive disorders are limited at present, but it is likely that the patterns emerging in CML will be applicable to other disease models.

\section{What is the mechanism of drug resistance?}

Three broad mechanisms may result in the restoration of kinase activity: (1) decreased intracellular levels of imatinib; (2) increased expression of the kinase; or (3) intrinsic changes in the kinase that affect its drug interaction or kinase activity.

MDR1 overexpression causing drug efflux (Mahon et al, 2003) has been shown to cause imatinib resistance in $\mathrm{Ph}+$ cell lines in vitro. The binding of imatinib to $\alpha_{1}$ acid glycoprotein has been reported to reduce the availability of the drug in vivo, with a demonstration of resistance in vitro (Gambacorti-Passerini et al, 2002). Low levels of imatinib have been reported in cerebrospinal fluid (Petzer et al, 2002), suggesting that this may be a 'sanctuary' site for residual disease.

Increased levels of BCR-ABL kinase, related to genomic amplification of the $B C R-A B L$ gene, or increased levels of expression has been observed. Importantly, an in vitro model demonstrated that exposure to low levels of imatinib promoted the development of genomic amplification, whereas effective drug levels did not (Le Coutre et al, 2000).

Finally, mutations in BCR-ABL may impair imatinib binding. This mechanism has perhaps been most widely studied and appears to be the most common mechanism of resistance in clinical practice (Gorre et al, 2001; Branford et al, 2002; Hochhaus et al, 2002; Shah et al, 2002; Branford et al, 2003).

To study the frequency of point mutations in $B C R-A B L, C M L$ patients were screened with sequencing of the $A B L$ kinase domain (Branford et al, 2003). All had received at least 6 months of imatinib therapy and were studied regardless of response. Mutations were found in 27 out of 144 patients and were associated with acquired resistance in $89 \%$ and with shortened survival.

In contrast, point mutations in $B C R-A B L$ are not commonly seen in primary refractory patients. In a separate study (Branford et al, 2002), only one out of $10 \mathrm{CML}$ patients with primary resistance to imatinib therapy had a $B C R-A B L$ mutation, suggesting that a different mechanism is responsible in this setting.

\section{Are all mutations equally important?}

There are limited data regarding the clinical significance of each individual mutation, but overall, their emergence in imatinib resistance indicates an association with poor prognosis. In CML patients treated with imatinib, emergence of mutations at aminoacid positions $250-255$, which form the adenosine triphosphatebinding loop (P-loop), carried an especially poor prognosis with 12 of $13(92 \%)$ dying at a median of 18 weeks from the detection of the mutation (Branford et al, 2003). Among 14 patients with nonP-loop mutations only three $(21 \%)$ died, with a similar follow-up from the time of detection.

The in vitro significance of individual mutations can be assessed more readily. Methods include inhibition of substrate phosphorylation and inhibition of cell culture. Reported $\mathrm{IC}_{50}$ values of clinically detected mutations are presented in Table 2 . These values are derived from in vitro cell lines engineered to express a specific mutant $B C R-A B L$ gene. For comparison, the mean plasma trough concentration of imatinib $400 \mathrm{mg}$ daily is $1.46 \mu \mathrm{M}$ (Corbin et al, 2003). CML mutant clones with an $\mathrm{IC}_{50}$ close to or below this value should be more likely to respond well to dose escalation.

Gambacorti-Passerini et al (2003) divide the BCR-ABL mutations into groups according to the functional regions of the molecule where they occur. In the first group, mutations such as T315I are in the imatinib-binding site. Other mutations involve the P-loop (e.g. E255 K) and presumed regulatory regions of the enzyme (e.g. M351T) remote from the imatinib-binding site.

Heinrich et al (2002c) suggest a similar classification of the KITactivating mechanisms of GIST. The major group of abnormalities involves regulatory portions of KIT, so the imatinib-binding region is unaffected. Hopefully, a better understanding of the C-KIT mutations present at diagnosis will help optimise both patient selection and tailoring of therapy. As may occur in the accelerated phase of CML, they also present evidence for the acquisition of additional karyotypic abnormalities in more advanced GIST. Such abnormalities may be predicted to augment the KIT-dependent transformation or confer KIT-independent malignant potential. However, the precise molecular mechanisms underlying acquired imatinib resistance in GIST are yet to be elucidated.

Unlike GIST, in systemic mastocytosis activation of KIT is typically associated with point mutations in the enzymatic region of the molecule. The most common of these mutations (D816 V) shows no response to imatinib in vitro (Zermati et al, 2003), while the proliferation of normal mast cells containing wild-type C-KIT was significantly inhibited. It is thought that the D816V mutation interferes with the interaction of imatinib and its KIT binding site. This finding is analogous to T315I in CML, which disrupts the noncovalent interactions essential for the binding of imatinib to the BCR-ABL kinase.

In idiopathic hypereosinophilic syndrome (Cools et al, 2003), there is another parallel to the CML experience in that acquired drug resistance was observed in one patient with emergence of a point mutation in PDGFRA-FIP1L1, again showing structural 
Table $2 \quad I C_{50}$ values for BCR-ABL mutations

IC50 ( $\mu \mathrm{M}$ imatinib)

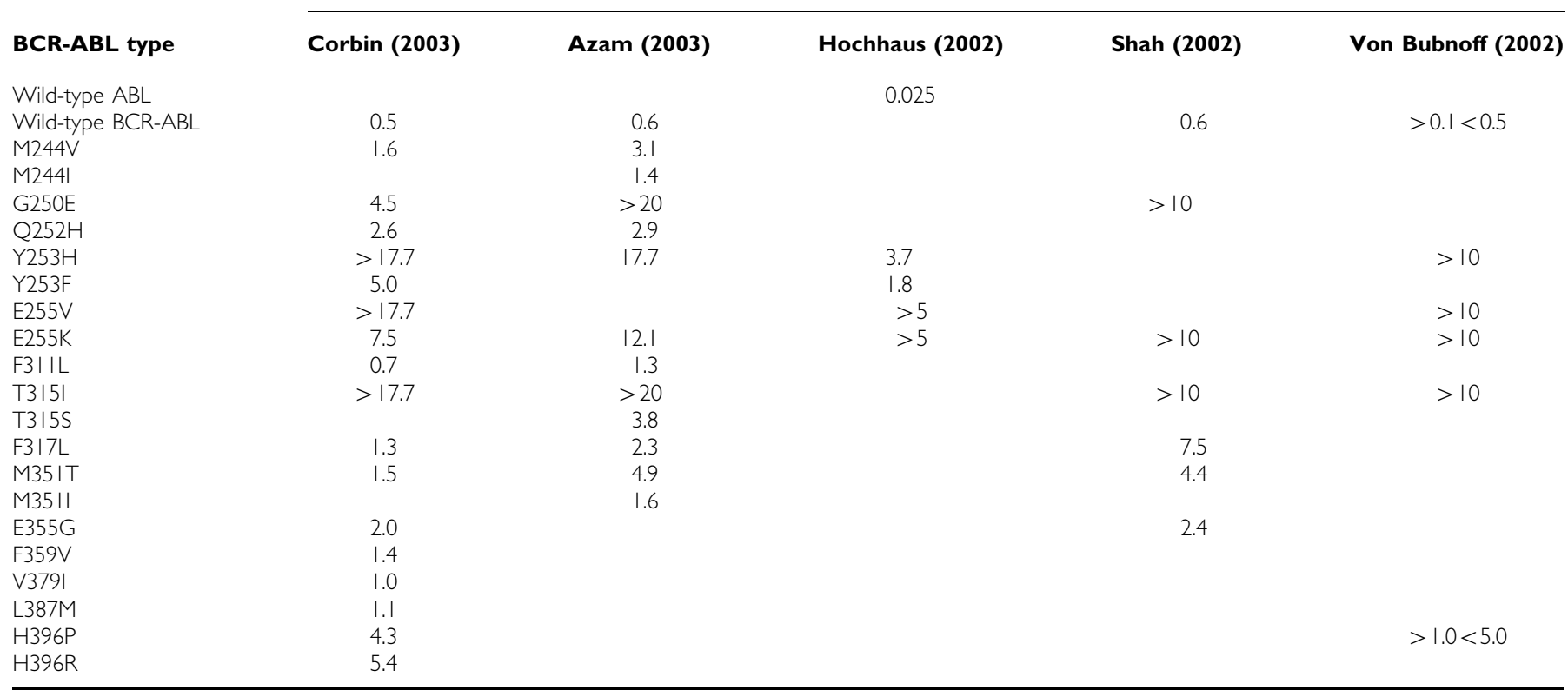

analogy to the T315I mutation of $B C R-A B L$. When the $\mathrm{IC}_{50}$ of this mutation was tested, it was found to show a 3-log increase from wild type.

\section{When do resistant mutations arise?}

It seems that at least in some cases of CML, mutations conferring resistance are in fact present in a small number of leukaemic cells prior to treatment and are positively selected by imatinib therapy. Interpretation of studies investigating this problem is complicated by the use of different methodologies with varying sensitivity. However, four patients with primary cytogenetic refractoriness had $B C R-A B L$ mutations identified using direct cDNA sequencing (Roche-Lestienne et al, 2002). Retrospective analysis of pretreatment specimens using allele-specific oligonucleotide PCR (ASOPCR) was able to demonstrate low levels of mutant cDNA in all four cases, indicating clonal selection. Similarly, von Bubnoff et al (2002) noted an increase in the proportion of mutant mRNA with sequential monitoring of relapsing patients.

Further evidence in support of this hypothesis comes from the finding that the duration of disease prior to commencement of imatinib is a significant predictor of resistance-conferring mutations (Branford et al, 2003). In a group of 144 patients classified according to disease phase at commencement of imatinib, no early chronic phase patients had detectable mutations, while $22 \%$ of late chronic phase patients carried mutations. Furthermore, patients who started imatinib therapy more than 4 years from diagnosis had a higher incidence of mutations $(41 \%)$ than those treated within 4 years $(9 \%)$.

\section{Can imatinib cure CML?}

Despite excellent initial responses to imatinib, it is unclear whether long-term control of chronic phase CML will be achieved with monotherapy. Although imatinib has been shown to promote apoptosis, there are in vitro data indicating that primitive $\mathrm{Ph}+$ stem cells not undergoing mitosis remain viable following exposure to the drug (Graham et al, 2002). Such cells could provide a therapy-resistant pool responsible for late relapse.
In advanced phases of CML, there may be secondary oncogenic abnormalities (e.g. P53 mutations) that change the biologic behaviour of the CML clone. Emergence of BCR-ABL-independent pathways supporting proliferation or resistance to apoptosis will inevitably diminish the efficacy of imatinib monotherapy.

\section{Can imatinib combination therapy overcome resistance?}

There is significant in vitro evidence indicating synergism of combinations of imatinib with conventional cytotoxics and newer biological therapies. Inhibition of heat shock protein, hsp90, and histone deacetylase results in degradation of BCR-ABL and induction of apoptosis in imatinib-resistant CML cell lines and shows synergism with imatinib (Schad et al, 2002; Nimmanapalli et al, 2003). Targeting alternative pathways of signal transduction, for example with farnesyl transferase inhibitors, also shows promise in imatinib-resistant CML cell lines (Hoover et al, 2002; Topaly et al, 2002).

Following on from in vitro studies, there are a number of preliminary reports of Phase I/II trials in imatinib-resistant CML using imatinib with gemtuzumab anti-CD33 monoclonal antibody (Sallah et al, 2002), imatinib with farnesyl transferase inhibitor, lonafarnib (Cortes et al, 2002a), and imatinib with cytotoxics (Mauro et al, 2002; Fruehauf et al, 2003; Maloisel et al, 2003). Overall, the main toxicity of combination therapy was increased myelosuppression, although this was generally well-tolerated.

In newly diagnosed chronic phase CML, trials combining imatinib and interferon $\alpha$ (Baccarani et al, 2002; Hochhaus et al, 2003) or imatinib and cytarabine (Cornelissen et al, 2002; Gardembas et al, 2002) are in progress. It seems likely that combination approaches will lead to a lower incidence of resistance, but this remains to be tested formally.

\section{IMPLICATIONS FOR CANCER THERAPY}

The use of imatinib in CML has been a striking success and has spurred an increase in research to develop molecular-based therapies in a range of conditions. What has this experience taught us about the use of kinase inhibitors in cancer therapy? Firstly, it is worth noting that some observations may be unique to CML. 
Most cancers are driven by multiple aberrant pathways and blockade of a single pathway may not represent effective monotherapy. Thus, the remarkable activity of imatinib as monotherapy may not be observed in most cancer settings. However, some key observations are likely to have broader implications:

(1) Experience in CML, and more recently in GIST and myeloproliferative disorders, indicates the importance of identifying a molecular target that can be inhibited and that also provides a critical transforming signal for tumour cells. This needs to be distinguished from tumours that simply express a potential target kinase, but are not critically dependent upon the kinase pathway.

(2) Blockade of a kinase that provides a significant growth signal in malignant cells may nullify the proliferative advantage of a tumour, but may not induce apoptosis. In CML, the amount of leukaemia present in the blood and marrow falls rapidly over the first few months of imatinib therapy, but residual leukaemia is usually still detectable with longer follow-up. This is the predicted pattern of response for an agent that blocks proliferation but does not induce cell death in leukaemic stem cells. The stem cell population may remain relatively intact because they are generally quiescent and not dependent on overactive kinase activity for survival. Combination therapy with a second agent capable of inducing apoptosis, or inducing cell division in quiescent cells may prove highly effective.

(3) Molecular diagnostics are playing an increasingly important role in the assessment of malignancy. At least in myeloproliferative disorders, and perhaps also in GIST, there is potential for patients with a similar clinicopathological presentation to harbour differing genetic abnormalities involving related tyrosine kinase pathways. This emphasises the need for accurate genetic diagnosis wherever possible. Molecular diagnosis will also improve our capacity to monitor disease response.
(4) Ideally, patients should be selected on the basis of in vitro testing to establish that their tumour is effectively targeted. Assessment of a kinase-dependent malignancy could include a screen for kinase mutations or polymorphisms that prevent binding of the kinase inhibitor and/or determination of the $\mathrm{IC}_{50}$. This would enable both appropriate use of the kinase inhibitor and identification of patients who will benefit from dose escalation or combination therapies. Optimal dosing should be based on extensive pharmacokinetic studies with verification of optimal target blockade. Where tumour tissue is available, PCR-based detection of drug-resistant mutations should be a component of monitoring, so that necessary changes to therapy may be initiated early.

(5) The development of acquired resistance is a significant concern in the CML setting, with over 20 possible mutations in BCR-ABL capable of leading to resistance. This illustrates the potential limitation of monotherapy using a highly specific kinase inhibitor that is likely to be relevant for many cancers. A similar observation of resistance due to kinase point mutation has been reported in a patient receiving imatinib for idiopathic hypereosinophilic syndrome.

(6) In CML, imatinib has its highest response rate when used soon after diagnosis, while resistant kinase mutations increase in frequency with disease duration and advanced phase of disease. Early and effective kinase inhibition may also be crucial to optimise treatment outcomes in other kinasedependent malignancies.

(7) Most importantly, careful elucidation of the cause of resistance in CML has led to detailed understanding of how the kinase works and how it interacts with inhibitors. This understanding has contributed to the development of new BCR-ABL inhibitors designed to be less susceptible to inactivation by a single amino acid substitution as well as providing an additional rationale for combination therapy. Similar detailed analysis of the cause of resistance with other kinase inhibitors is likely to be equally valuable.

\section{REFERENCES}

Apperley JF, Gardembas M, Melo JV, Russell-Jones R, Bain BJ, Baxter EJ, Chase A, Chessells JM, Colombat M, Dearden CE, Dimitrijevic S, Mahon F-X, Marin D, Nikolova Z, Olavarria E, Silberman S, Schultheis B, Cross NCP, Goldman JM (2002) Response to imatinib mesylate in patients with chronic myeloproliferative diseases with rearrangements of the plateletderived growth factor receptor beta. N Engl J Med 347(7): 481-487

Ault P, Cortes J, Koller C, Kaled ES, Kantarjian H (2002) Response of idiopathic hypereosinophilic syndrome to treatment with imatinib mesylate. Leukemia Res 26(9): $881-884$

Azam M, Latek RR, Daley GQ (2003) Mechanisms of autoinhibition and STI-571/imatinib resistance revealed by mutagenesis of BCR-ABL. Cell 112: $831-843$

Baccarani M, Trabacchi E, Bassi S, Bonifazi F, De Vivo A, Martinelli G, Alberti D, Fincato G, Ford JM, Saglio G, Amabile M, Testoni N, Rosti G, Tura S (2002) Results of a phase II trial testing a combination of imatinib and pegylated $\alpha 2 \mathrm{~b}$ interferon in $\mathrm{Ph}+$ chronic myeloid leukemia in early chronic phase. The early cytogenetic response is significantly risk related. American Society of Hematology Annual Meeting Abstract Number 348

Baxter EJ, Hochhaus A, Bolufer P, Reiter A, Fernandez JM, Senent L, Cervera J, Moscardo F, Sanz MA, Cross NCP (2002) The t(4;22)(q12;q11) in atypical chronic myeloid leukaemia fuses BCR to PDGFRA. Hum Mol Genet 11(12): $1391-1397$

Branford S, Rudzki Z, Walsh S, Grigg A, Arthur C, Taylor K, Herrmann R, Lynch KP, Hughes TP (2002) High frequency of point mutations clustered within the adenosine triphosphate-binding region of BCR/ABL in patients with chronic myeloid leukemia or Ph-positive acute lymphoblastic leukemia who develop imatinib (STI571) resistance. Blood 99(9): $3472-3475$
Branford S, Rudzki Z, Walsh S, Parkinson I, Grigg A, Szer J, Taylor K, Herrmann R, Seymour JF, Arthur C, Joske D, Lynch KP, Hughes TP (2003) Detection of $B C R-A B L$ mutations in patients with CML treated with imatinib is virtually always accompanied by clinical resistance, and mutations in the ATP phosphate-binding loop (P-loop) are associated with a poor prognosis. Blood 102(1): 276-283

Buchdunger E, O'Reilly T, Wood J (2002) Pharmacology of imatinib (STI571). Eur J Cancer 38(S5): 28-36

Claesson-Welsh L (1994) Platelet-derived growth factor receptor signals. $J$ Biol Chem 269(51): 32023-32026

Cools J, DeAngelo DJ, Gotlib J, Stover EH, Legare RD, Cortes J, Kutok J, Clark J, Galinsky I, Griffin JD, Cross NCP, Tefferi A, Malone J, Alam R, Schrier SL, Schmid J, Rose M, Vandenberghe P, Verhoef G, Boogaerts M, Wlodarska I, Kantarjian H, Marynen P, Coutre SE, Stone R, Gilliland DG (2003) A tyrosine kinase created by fusion of the PDGFRA and FIP1L1 genes as a therapeutic target of imatinib in idiopathic hypereosinophilic syndrome. N Engl J Med 348(13): 1201-1214

Corbin AS, La Rosee P, Stoffregen EP, Druker BJ, Deininger MW (2003) Several Bcr-Abl kinase domain mutants associated with imatinib mesylate resistance remain sensitive to imatinib. Blood 101(11): $4611-4614$

Cornelissen JJ, Verhoef GEG, Straetmans N, Smit WM, van Marwijk Kooij M, Wittebol S, van Oers MHJ, Kluin-Nelemans JC, Westveer PHM, Lowenberg B, Ossenkoppele G (2002) A dose-escalating phase I/II study of imatinib and cytarabin in first chronic phase chronic myeloie leukemia. American Society of Hematology Annual Meeting Abstract Number 349

Cortes J, Daley G, Talpaz M, O’Brien S, Garcia-Manero G, Giles F, Faderl S, Pate O, Zaknoen S, Kantarjian H (2002a) Pilot study of SCH66336 
(lonafarnib), a farnesyl transferase inhibitor in patients with chronic myeloid leukemia in chronic or accelerated phase resistant or refractory to imatinib. American Society of Hematology Annual Meeting Abstract Number 614

Cortes J, Giles F, O'Brien S, Talpaz M, Thomas D, Keating M, GarciaManero G, Faderl S, Estey E, Letvak L, Bochinski K, Kantarjian H (2002) Treatment with imatinib mesylate in patients with refractory or relapsed acute myeloid leukemia, high-risk myelodysplastic syndrome or myeloproliferative disorders. American Society of Hematology Annual Meeting Abstract Number 3160

Cortes J, Giles F, O'Brien S, Thomas D, Garcia-Manero G, Rios MB, Faderl S, Verstovsek S, Ferrajoli A, Freireich EJ, Talpaz M, Kantarjian H (2003) Result of high-dose imatinib mesylate in patients with Philadelphia chromosome-positive chronic myeloid leukemia after failure of interferon- $\alpha$. Blood 102(1): $83-86$

Dai CH, Krantz SB, Green WF, Gilbert HS (1994) Polycythaemia vera III. Burst-forming units - erythroid (BFU-E) response to stem cell factor and c-kit receptor expression. Br J Haematol 86: 12-21

Demetri GD, von Mehren M, Blanke CD, van den Abbeele AD, Eisenberg B, Roberts PJ, Heinrich MC, Tuveson DA, Singer S, Janicek M, Fletcher JA Silverman SG, Silberman SL, Capdeville R, Kiese B, Peng B, Dimitrijevic S, Druker BJ, Corless C, Fletcher CDM, Joensuu H (2002) Efficacy and safety of imatinib mesylate in advanced gastrointestinal stromal tumors. $N$ Engl J Med 347(7): 472-480

Fischer T, Beck J, Duyster J, Peschel C, Mueller-Navia J, Jaeger E, Knuth A, Gschaidmeier H, Huber C (2002) A phase II pilot study of Glivec in patients with c-kit positive acute myeloid leukemia. American Society of Hematology Annual Meeting Abstract Number 2204

Fruehauf S, Buss EC, Hehlmann R, Hochhaus A, Fischer T, Emmerich B, Gschaidmeier H (2003) Interim results of a multicenter phase I/II trial of the combination of imatinib mesylate with mitoxantrone/etoposide and cytarabine in patients with chronic myeloid leukemia in myeloid blast crisis. European Hematology Association Annual Meeting Abstract Number 595

Gambacorti-Passerini CB, Gunby RH, Piazza R, Galietta A, Rostagno R, Scapozza L (2003) Molecular mechanisms of resistance to imatinib in Philadelphia-chromosome-positive leukaemias. Lancet Oncol 4: $75-85$

Gambacorti-Passerini CB, Rossi F, Verga M, Ruchatz H, Gunby R, Frapolli R, Zucchetti M, Scapozza L, Bungaro S, Tornaghi L, Rossi F, Pioltelli P, Pogliani E, D'Incalci M, Corneo G (2002) Differences between in vivo and in vitro sensitivity to imatinib of $\mathrm{Bcr} / \mathrm{Abl}+$ cells obtained from leukaemic patients. Blood Cells, Mol Dis 28(3): 361-372

Gardembas M, Rousselot P, Tulliez M, Vigier M, Buzyn A, Rigal-Huguet F, Legros L, Michallet M, Berthou C, Najman A, Maloisel F, Mahon F-X, Facon T, Berthaud P, Guilhot J, Guilhot F (2002) Imatinib and cytarabine is an effective regimen in Philadelphia-positive chronic myelogenous leukaemia chronic phase patients. American Society of Hematology Annual Meeting Abstract Number 351

Gleich GJ, Leiferman KM, Pardanani A, Tefferi A, Butterfield JH (2002) Treatment of hypereosinophilic syndrome with imatinib mesilate. Lancet 359: $1577-1578$

Gorre ME, Mohammed M, Ellwood K, Hsu N, Paquette R, Rao PN, Sawyers CL (2001) Clinical resistance to STI-571 cancer therapy caused by BCR$\mathrm{ABL}$ gene mutation or amplification. Science 293: 876-880

Graham SM, Jørgensen HG, Allan E, Pearson C, Alcorn MJ, Richmond L, Holyoake TL (2002) Primitive, quiescent, Philadelphia-positive stem cells from patients with chronic myeloid leukemia are insensitive to STI571 in vitro. Blood 99(1): 319-325

Guerif F, Cadoret V, Plat M, Magistrini M, Lansac J, Hochereau-de Reviers MT, Royere D (2002) Characterization of the fertility of Kit haplodeficient male mice. Int J Androl 25: 358-368

Hasan S, Dinh K, Lombardo F, Dawkins F, Kark J (2003) Hypopigmentation in an African patient treated with imatinib mesylate: a case report. J Natl Med Assoc 95(8): 722-724

Heinrich MC, Blanke CD, Druker BJ, Corless CL (2002a) Inhibition of KIT tyrosine kinase activity: a novel molecular approach to the treatment of KIT-positive malignancies. J Clin Oncol 20(6): 1692-1703

Heinrich MC, Corless CL, Blanke C, Demetri GD, Joensuu H, von Mehren M, McGreevey MS, Wait CL, Griffith D, Chen C-J, Haley A, Kiese B Druker B, Roberts P, Eisenberg B, Singer S, Silberman S, Dimitrijevic S, Fletcher CD, Fletcher JA (2002b) KIT mutational status predicts clinical response to STI571 in patients with metastatic gastrointestinal stromal tumors (GISTs). American Society of Clinical Oncology Annual Meeting Abstracts
Heinrich MC, Corless CL, Duensing A, McGreevey MS, Chen C-J, Joseph N, Singer S, Griffith DJ, Haley A, Town A, Demetri GD, Fletcher CDM, Fletcher JA (2003) PDGFRA activating mutations in gastrointestinal stromal tumors. Science 299: 708-710

Heinrich MC, Rubin BP, Longley BJ, Fletcher JA (2002c) Biology and genetic aspects of gastrointestinal stromal tumors: KIT activation and cytogenetic alterations. Hum Pathol 33(5): 484-495

Hochhaus A, Bostel T, Mueller MC, Merx K, Berger U, Hehlmann R, Fischer T, Beck J, Bruemmendorf T, Lengerke C, Schoch C, Burchert A, Neubauer A, Rose MT, Gschaidmeier H (2003) Combination therapy of chronic phase chronic myelogenous leukemia with imatinib and pegylated interferon 2a (Pegasys). European Hematology Association Annual Meeting Abstract Number 582

Hochhaus A, Kreil S, Corbin AS, La Rosee P, Muller MC, Lahaye T, Hanfstein B, Schoch C, Cross NCP, Berger U, Gschaidmeier $\mathrm{H}$, Druker BJ, Hehlmann R (2002) Molecular and chromosomal mechanisms of resistance to imatinib (STI571) therapy. Leukemia 16: $2190-2196$

Hoover RR, Mahon F-X, Melo J, Daley GQ (2002) Overcoming STI571 resistance with the farnesyl transferase inhibitor SCH66336. Blood 100(3): $1068-1071$

Hou L, Panthier J-J, Arnheiter H (2000) Signaling and transcriptional regulation in the neural crest-derived melanocyte lineage: interactions between KIT and MITF. Development 127: 5379-5389

Hughes TP, Branford S (2003) Molecular monitoring of chronic myeloid leukemia. Sem Hematol 40(2): 62-68

Jones CM, Dickinson TM (2003) Polycythemia vera responds to imatinib mesylate. Am J Med Sci 325(3): 149-152

Kantarjian H, Sawyers C, Hochhaus A, Guilhot F, Schiffer C, GambacortiPasserini C, Niederwieser D, Resta D, Capdeville R, Zoellner U, Talpaz M, Druker B (2002) Hematologic and cytogenetic responses to imatinib mesylate in chronic myelogenous leukemia. $N$ Engl J Med 346(9): $645-652$

Kantarjian HM, Talpaz M, O’Brien S, Giles F, Garcia-Manero G, Faderl S, Thomas D, Shan J, Rios MB, Cortes J (2003) Dose escalation of imatinib mesylate can overcome resistance to standard-dose therapy in patients with chronic myelogenous leukemia. Blood 101(2): $473-475$

Kindler T, Breitenbuecher F, Marx A, Hess G, Gschaidmeier H, Gamm H, Kirkpatrick CJ, Huber C, Fischer T (2003) Sustained complete hematologic remission after administration of the tyrosine kinase inhibitor imatinib mesylate in a patient with refractory, secondary AML. Blood 101(8): 2960-2962

Le Coutre P, Tassi E, Varella-Garcia M, Barni R, Mologna L, Cabrita G, Marchesi E, Supino R, Gambacorti-Passerini CB (2000) Induction of resistance to the Abelson inhibitor STI571 in human leukemic cells through gene amplification. Blood 95(5): 1758-1766

Li B, Boast S, de los Santos K, Schieren I, Quiroz M, Teitelbaum SL, Tondravi MM, Goff SP (2000) Mice deficient in Abl are osteoporotic and have defects in osteoblast maturation. Nat Genet 24(3): 304-308

Mahon F-X, Belloc F, Lagarde V, Chollet C, Moreau-Gaudry F, Reiffers J, Goldman JM, Melo JV (2003) MDR1 gene overexpression confers resistance to imatinib mesylate in leukemia cell line models. Blood 101(6): $2368-2373$

Maloisel EG, Zamfir A, Koumarinou A, Dufour P, Rousselot P (2003) Subcutaneous homoharringtonine in combination with imatinib mesylate (STI571) in patients with STI571-resistant chronic myelogenous leukemia. European Hematology Association Annual Meeting Abstract Number 587

Mauro MJ, Deininger MW, O'Dwyer ME, Maziarz RT, Walker T, Kurilik G, Druker BJ (2002) Phase I/II study of arsenic trioxide (Trisenox) in combination with imatinib mesylate (Gleevec) in patients with Gleevec-resistant chronic myelogenous leukemia in chronic phase. American Society of Hematology Annual Meeting Abstract Number 3090

Merx K, Mueller MC, Kreil S, Lahaye T, Paschka P, Schoch C, Weisser A, Kuhn C, Berger U, Gschaidmeier H, Hehlmann R, Hochhaus A (2002) Early reduction of BCR-ABL mRNA transcript levels predicts cytogenetic response in chronic phase CML patients treated with imatinib after failure of interferon $\alpha$. Leukemia 16: $1579-1583$

Nimmanapalli R, Fuino L, Bali P, Gasparetto M, Glozak M, Tao J, Moscinski L, Smith C, Wu J, Jove R, Atadja P, Bhalla K (2003) Histone deacetylase inhibitor LAQ824 both lowers expression and promotes degradation of $\mathrm{Bcr}-\mathrm{Abl}$ and induces apoptosis of imatinib mesylate-sensitive or refractory chronic myelogenous leukemia - blast crisis cells. Cancer Res 63(16): $5126-5135$ 
O'Brien SG, Guilhot F, Larson RA, Gathmann I, Baccarani M, Cervantes F, Cornelissen JJ, Fischer T, Hochhaus A, Hughes TP, Lechner K, Nielsen JL, Rousselot P, Reiffers J, Saglio G, Shepherd J, Simonsson B, Gratwohl A, Goldman JM, Kantajian H, Taylor K, Verhoef G, Bolton AE, Capdeville $\mathrm{R}$, Druker BJ (2003) Imatinib compared with interferon and low-dose cytarabine for newly diagnosed chronic phase chronic myeloid leukaemia. N Engl J Med 348(11): 994-1004

Ottmann OG, Druker BJ, Sawyers CL, Goldman JM, Reiffers J, Silver RT, Tura S, Fischer T, Deininger MW, Schiffer CA, Baccarani M, Gratwohl A, Hochhaus A, Hoelzer D, Fernandes -Reese S, Gathmann I, Capdeville R, O'Brien S (2002) A phase 2 study of imatinib in patients with relapsed or refractory Philadelphia chromosome-positive acute lymphoid leukemias. Blood 100(6): 1965-1971

Pardanani A, Reeder T, Elliott M, Li C-Y, Tefferi A (2002) Imatinib therapy for systemic mast cell disease. American Society of Hematology Annual Meeting Abstract Number 255

Petzer AL, Gunsilius E, Hayes M, Stockhammer G, Duba HC, Schneller F, Grunewald K, Poewe W, Gastl G (2002) Low concentrations of STI571 in the cerebrospinal fluid: a case report. Br J Haematol 117(3): 623-625

Ratajczak MZ, Luger SM, De Riel K, Abrahm J, Calabretta B, Gewirtz AM (1992) Role of the KIT protooncogene in normal and malignant human haematopoiesis. Proc Natl Acad Sci USA 89(5): 1710-1714

Roche-Lestienne C, Soenen-Cornu V, Grardel-Duflos N, Lai, J-L, Philippe N, Facon T, Fenaux P, Preudhomme C (2002) Several types of mutations of the $\mathrm{Abl}$ gene can be found in chronic myeloid leukemia patients resistant to STI571, and they can pre-exist to the onset of treatment. Blood 100(3): 1014-1018

Rubin BP, Singer S, Tsao C, Duensing A, Lux ML, Ruiz R, Hibbard MK, Chen CJ, Xiao S, Tuveson DA, Demetri GD, Fletcher CD, Fletcher JA (2001) KIT activation is a ubiquitous feature of gastrointestinal stromal tumors. Cancer Res 61(22): 8118-8121

Saikia T, Naresh KN, Advani SH, Deshmukh C (2002) Generalized hypopigmentation of the skin following imatinib mesylate in chronic myeloid leukemia - interference with melanin metabolism. American Society of Hematology Annual Meeting Abstract Number 4809

Sallah AS, Wan JP, Nguyen NP, Sigounas G (2002) Combination imatinib and gemtuzumab ozogamicin in patients with chronic myeloid leukemia in myeloid blast crisis. American Society of Hematology Annual Meeting Abstract Number 4824

Sawyers CL, Hochhaus A, Feldman E, Goldman JM, Miller CB, Ottmann OG, Schiffer CA, Talpaz M, Guilhot F, Deininger MW, Fischer T, O'Brien SG, Stone RM, Gambacorti-Passerini C, Russell NH, Reiffers JJ, Shea TC, Chapuis B, Coutre S, Tura S, Morra E, Larson RA, Saven A, Peschel C, Gratwohl A, Mandelli F, Ben-Am M, Gathmann I, Capdeville R, Paquette RL, Druker BJ (2002) Imatinib induces hematologic and cytogenetic responses in patients with chronic myelogenous leukemia in myeloid blast crisis: results of a phase II study. Blood 99(10): $3530-3539$

Scappini B, Onida F, Kantarjian HM, Dong L, Verstovsek S, Keating MJ, Beran M (2001) Effects of signal transduction inhibitor 571 in acute myelogenous leukemia cells. Clin Cancer Res 7: 3884-3893
Schad M, Topaly J, Laufs S, Zeller WJ, Melo JV, Fruehauf S (2002) Combination of Hsp90 blocker 17AAG and imatinib shows synergistic activity in imatinib-resistant chronic myelogenous leukemia cells. American Society of Hematology Annual Meeting Abstract Number 1235 Shah NP, Nicoll JM, Nagar B, Gorre ME, Paquette RL, Kuriyan J, Sawyers CL (2002) Multiple BCR-ABL kinase domain mutations confer polyclonal resistance to the tyrosine kinase inhibitor imatinib (STI571) in chronic phase and blast crisis chronic myeloid leukemia. Cancer Cell 2: 117-125

Silver RT (2002) Imatinib mesylate reduces phlebotomy requirements in polycythemia vera. American Society of Hematology Annual Meeting Abstract Number 153

Singer S, Rubin BP, Lux ML, Chen C-J, Demetri GD, Fletcher CDM, Fletcher JA (2002) Prognostic value of KIT mutation type, mitotic activity and histologic subtype in gastrointestinal stromal tumors. J Clin Oncol 20(18): $3898-3905$

Talpaz M, Silver RT, Druker BJ, Goldman JM, Gambacorti-Passerini C, Guilhot F, Schiffer CA, Fischer T, Deininger MWN, Lennard AL, Hochhaus A, Ottmann OG, Gratwohl A, Baccarani M, Stone R, Tura S, Mahon F-X, Fernandes-Reese S, Gathmann I, Capdeville R, Kantarjian HM, Sawyers CL (2002) Imatinib induces durable hematologic and cytogenetic responses in patients with accelerated phase chronic myeloid leukemia: results of a phase 2 study. Blood 99(6): 1928-1937

Tefferi A, Mesa RA, Gray LA, Steensma DP, Camoriano JK, Elliott MA, Pardanani A, Ansell SM, Call TG, Colon-Otero G, Schroeder G, Hanson CA, Dewald GW, Kaufmann SH (2002) Phase 2 trial of imatinib mesylate in myelofibrosis with myeloid metaplasia. Blood 99(10): 3854-3856

Topaly J, Zeller WJ, Fruehauf S (2002) Potentiation of imatinib activity in chronic myelogenous leukemia cells by farnesyl transferase inhibitors. American Society of Hematology Annual Meeting Abstract Number 1233 van den Abbeele $\mathrm{AD}$, Badawi RD, Cliche J-P, Janicek MJ, Tetrault R, Spangler T, Potter A, Merriam P, Silberman S, Dimitrijevic S, Demetri GD (2002) 18F-FDG-PET predicts response to imatinib mesylate (Gleevec) in patients with advanced gastrointestinal stromal tumors (GIST) (2002). American Society of Clinical Oncology Annual Meeting Abstracts

Van Etten RA (1999) Cycling, stressed-out and nervous: cellular functions of c-Abl. Trends Cell Biol 9: 179-186

von Bubnoff N, Schneller F, Peschel C, Duyster J (2002) BCR-ABL gene mutations in relation to clinical resistance of Philadelphia-chromosomepositive leukaemia to STI571: a prospective study. Lancet 359(9): 487-491 Zermati Y, De Sepulveda P, Leger F, Letard S, Kersual J, Casteran N, Gorochov G, Dy M, Ribadeau Dumas A, Dorgham K, Parizot C, Bieche Y, Vidaud M, Lortholary O, Arock M, Hermine O, Dubreuil P (2003) Effect of tyrosine kinase inhibitor STI571 on the kinase activity of wild-type and various mutated c-kit receptors found in mast cell neoplasms. Oncogene 22(5): $660-664$

Zwaan CM, Miller M, Goemans BF, Haehlen K, van Wering E, Meshinchi S, Reinhardt D, Zimmermann M, Creutzig U, Kaspers GJL, Heinrich MC (2002) Frequency and clinical significance of c-kit exon 17 mutations in childhood acute myeloid leukemia. American Society of Hematology Annual Meeting Abstract Number 2952 